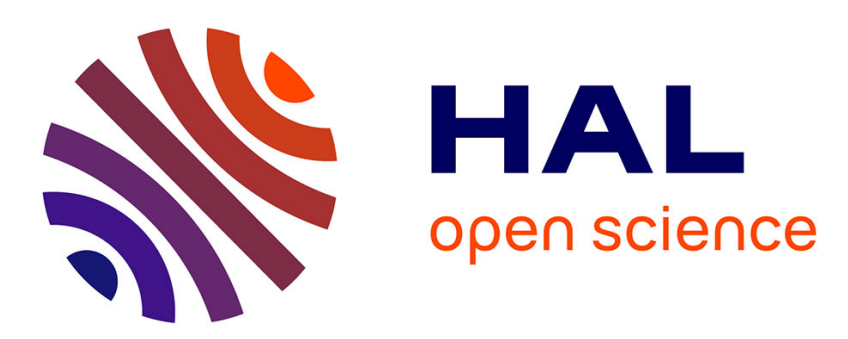

\title{
Analysis of the JAXA Nonequilibrium Infrared Emission Spectra for Mars Entry Conditions
}

\author{
Erwan Pannier, Christophe O. Laux
}

\section{To cite this version:}

Erwan Pannier, Christophe O. Laux. Analysis of the JAXA Nonequilibrium Infrared Emission Spectra for Mars Entry Conditions. Journal of Thermophysics and Heat Transfer, 2019, 33 (4), pp.1127-1131. 10.2514/1.T5646 . hal-02471012

\section{HAL Id: hal-02471012 \\ https://hal.science/hal-02471012}

Submitted on 7 Feb 2020

HAL is a multi-disciplinary open access archive for the deposit and dissemination of scientific research documents, whether they are published or not. The documents may come from teaching and research institutions in France or abroad, or from public or private research centers.
L'archive ouverte pluridisciplinaire HAL, est destinée au dépôt et à la diffusion de documents scientifiques de niveau recherche, publiés ou non, émanant des établissements d'enseignement et de recherche français ou étrangers, des laboratoires publics ou privés. 


\title{
Analysis of the JAXA nonequilibrium infrared emission spectra for Mars entry conditions
}

\author{
Erwan Pannier* \\ Laboratoire EM2C, CNRS UPR288, CentraleSupélec, Université Paris Saclay, 3 rue Joliot Curie, 91190 Gif sur Yvette, \\ France \\ Christophe O Laux ${ }^{\dagger}$ \\ Laboratoire EM2C, CNRS UPR288, CentraleSupélec, Université Paris Saclay, 3 rue Joliot Curie, 91190 Gif sur Yvette, \\ France
}

\begin{abstract}
Nonequilibrium infrared emission spectra representative of a Mars atmospheric entry mission are modeled using RADIS, a spectral code for $\mathrm{CO}$ and $\mathrm{CO}_{2}$ based on the HITEMP-2010 and CDSD-4000 databases. The modeled experimental data for the free-flow and the forebody radiation were obtained in the JAXA expansion tube facility. In the expanding flow, good agreement with the experimental data can be obtained using a slightly nonequilibrium distribution and a homogeneous flow. The model suggests that all three $\mathrm{CO}_{2}$ vibration modes share a same vibrational temperature slightly higher than the gas temperature. In the shock layer, the forebody radiation includes both $\mathrm{CO}_{2}$ and $\mathrm{CO}$ emission features. It can be correctly predicted by assuming thermal and chemical equilibrium at $4000 \pm 500 \mathrm{~K}$.
\end{abstract}

\section{Nomenclature}

$$
\begin{array}{ll}
p & =\text { pressure }[\mathrm{bar}] \\
T_{\text {rot }} & =\text { rotational temperature of the gas }[\mathrm{K}] \\
T_{\text {trans }} & =\text { translational temperature of the gas }[\mathrm{K}] \\
T_{v i b} & =\text { vibrational temperature of the gas }[\mathrm{K}] \\
T_{v i b_{1}}, T_{v i b_{2}}, T_{v i b_{3}} & =\text { for } \mathrm{CO}_{2}, \text { temperature of each vibration mode: symmetric, bending and asymmetric vibration, respectively }[\mathrm{K}] \\
x_{\mathrm{CO}}, x_{\mathrm{CO}_{2}} & =\text { mole fractions }
\end{array}
$$

*Ph.D student, CentraleSupélec, erwan.pannier@centralesupelec.fr

†Professor, CentraleSupélec, christophe.laux@centralesupelec.fr, AIAA Associate Fellow 


\section{Introduction}

$\mathrm{CO}_{2}$ radiation plays an important role in forebody and afterbody heating of vehicles entering the Martian atmosphere. In the forebody, the radiation is dominated by visible and $\mathrm{UV}$ emission of $\mathrm{CO}, \mathrm{CN}$ and $\mathrm{O}_{2}$ [2? ]. In the afterbody, the recombination of $\mathrm{CO}_{2}$ is responsible for a radiative heat flux larger than convective heating [3], but thee are still large uncertainties on the radiative fluxes [4]: on the eve of new Mars missions, a renewed computational [5] and experimental effort was engaged at NASA [4], JAXA [6] and UQ [7] to model nonequilibrium $\mathrm{CO}_{2}$ radiation.

The JAXA expansion tube experiment of Takayanagi et al. [6] was one of the first experiment to measure absolute intensity $\mathrm{CO}_{2}$ infrared spectra in an expanding flow. The experiment was performed in the JAXA HVST expansion-tube facility, with a model placed at the exit of the tube, and a flow velocity of $5.68 \mathrm{~km} / \mathrm{s}$. Using CFD simulations to reproduce the measured shock standoff distance, the authors determined the following nonequilibrium conditions in the free flow upstream of the model: $\mathrm{T}_{\text {trans }}=1690 \mathrm{~K}, \mathrm{~T}_{\mathrm{vib}}=4000 \mathrm{~K}, \mathrm{p}=17 \mathrm{mbar}, \mathrm{x}_{\mathrm{CO}_{2}}=0.61, \mathrm{x}_{\mathrm{CO}}=0.26, \mathrm{x}_{\mathrm{O}_{2}}=0.12$ and $\mathrm{x}_{\mathrm{O}}=0.01$. The authors also measured absolute emission spectra of the $4.2 \mu \mathrm{m}$ band of $\mathrm{CO}_{2}$ at three locations: in the free flow, in front of the model, and behind the model. Takayanagi et al. [6] attempted to fit the free flow experimental spectrum with the SPRADIAN code [8] assuming equilibrium at temperatures ranging from 1500 to $4000 \mathrm{~K}$. However, they obtained a surprisingly large disagreement for all conditions considered (see Fig. 22 in Ref. [6]). They attributed the discrepancies to flow heterogeneities and to a nonequilibrium vibrational distribution. The forebody radiation was not analyzed.

In this work, we reanalyze the nonequilibrium spectra measured by Takayanagi et al. [6]. We first consider the free-flow to confirm its nonequilibrium state. Then, the forebody radiation will be examined. The path length associated with the afterbody radiation is not clear, hence it is not studied in the present work.

Figure 1 shows the experimental configuration and measurement locations. The shock wave position (dashed) is inferred from the Schlieren images of Ref. [6]. The measurement locations are inferred from Fig.21 of Ref. [6]. The spectra were measured tangentially to the model so the total line-of-sight length is always $7 \mathrm{~cm}$. In front of the model (blue arrow in Fig. 1), part of the line-of-sight is in the free-flow (red portion) and part is in the shock layer (blue portion). Because of the model curvature, the distance to the model wall is not constant (see the upper part of Fig. 1, estimated from Fig. 17 of Ref. [6]) and the integration path is not homogeneous: in the following, we consider that the shock region is equivalent to a segment of uniform gas of length $1 \mathrm{~cm}$.

The spectra measured by Takayanagi et al. [6] in the free-flow and in front of the model are reproduced in Figure 2. 


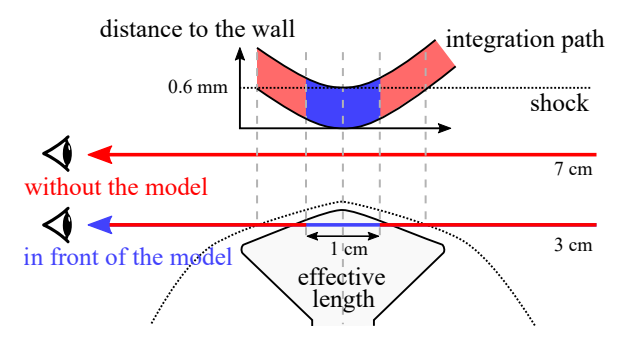

Fig. 1 Schematic of the measurement locations of Takayanagi et al. [6], without the model (red arrow) and in front of the model (blue arrow). Refer to text for more details.

They are red-shifted by $30 \mathrm{~nm}$ so as to match the $\mathrm{CO}_{2}$ bandhead in the later calculations. This shift could be attributed to a small offset in the experimental wavelength calibration procedure. For illustration purpose, the forebody emission (dashed, blue) is estimated in the optically thin approximation by subtracting the free-flow emission scaled down to $6 \mathrm{~cm}$ to the line-of-sight measurement in front of the model. In the later calculations, the full line-of-sight is calculated solving the radiative transfer equation.

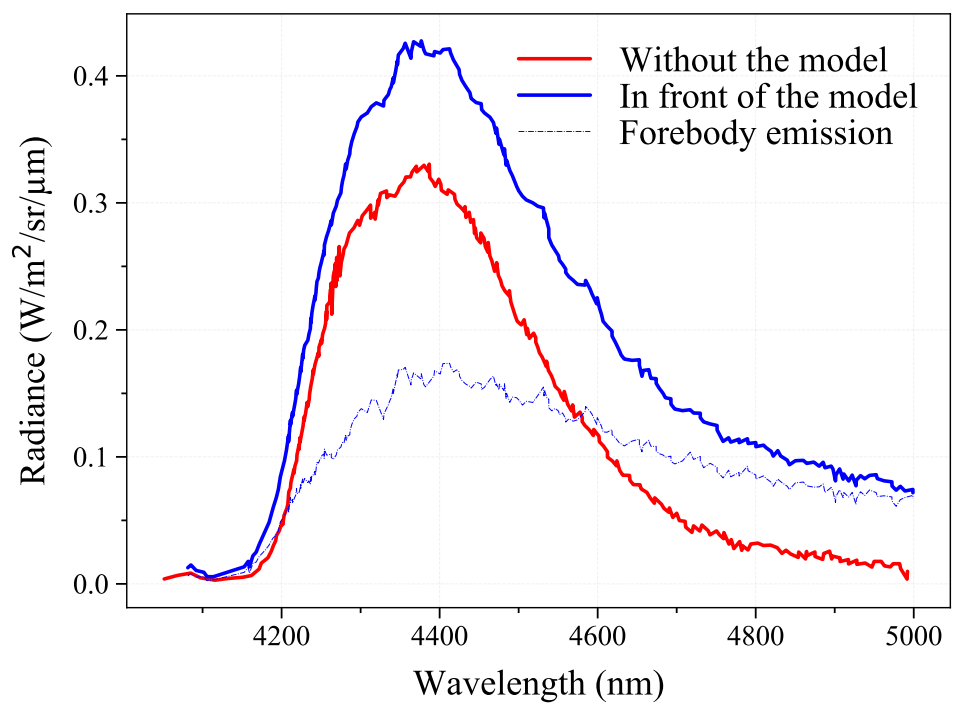

Fig. 2 IR radiation measured in the expansion-tube experiment of Ref. Takayanagi et al. [6] in the free flow (red) and in front of the entry model (solid blue). Forebody emission (dashed, blue) is estimated in the optically thin approximation.

\section{Spectral code}

The radiation of $\mathrm{CO}_{2}$ and $\mathrm{CO}$ radiation is modeled using RADIS $[9,10]$, an open-source nonequilibrium infrared line-by-line code. In Ref. [10], the RADIS solver was validated against infrared measurements from an equilibrium microwave torch [11], a low-pressure nonequilibrium laser discharge [12], an equilibrium RF plasma torch [13] and a NASA shock tube experiment [14]. RADIS takes HITRAN-like line databases as input, and either reads rovibrational 
energies from precomputed databases or calculates them from spectroscopic constants. RADIS can model a variety of vibrational population distributions (Boltzmann, Treanor, overpopulation factors...), as well as line-of-sight emission spectra of heterogeneous media: for these simulations, the radiative transfer equation is solved along multiple slabs, each slab being assumed to have uniform thermochemical properties.

In this work, the CDSD-4000 line database [15] is used to model $\mathrm{CO}_{2}$ radiation at high temperature $(\mathrm{T}>2200 \mathrm{~K})$, and the HITEMP-2010 database [16] for $\mathrm{CO}$ radiation or $\mathrm{CO}_{2}$ radiation at lower temperature ( $\left.\mathrm{T} \leq 2200 \mathrm{~K}\right)$. A sensitivity analysis [10] showed that HITEMP-2010 and CDSD-4000 give similar results at $\mathrm{T} \leq 2200 \mathrm{~K}$ for the $4.2 \mu \mathrm{m} \mathrm{CO}_{2}$ band. The rovibrational energies of $\mathrm{CO}$ are calculated with a coupled rotating vibrator model. Dunham expansions are calculated with the spectroscopic constants of Ref. [17], which include rotational-vibrational interaction terms for seven isotopes of $\mathrm{CO}$. The rovibrational energies of $\mathrm{CO}_{2}$ are calculated with an uncoupled rotating vibrator model. The spectroscopic constants reviewed by Klarenaar et al. [18] are used for the three main isotopes of $\mathrm{CO}_{2}$, and do not include rotational-vibrational interaction terms. Boltzmann distributions are used for both the rotational and the vibrational levels.

Nonequilibrium $\mathrm{CO}_{2}$ spectra are calculated with a two-temperature model $\left(\mathrm{T}_{\mathrm{vib}}, \mathrm{T}_{\mathrm{rot}}\right)$. In a first model, the rotational temperature is assumed to be equal to the translational temperature, and the three vibrational modes of $\mathrm{CO}_{2}$ are assumed to be in equilibrium, i.e.:

$$
\begin{gathered}
T_{\text {rot }}=T_{\text {trans }} \\
T_{v i b}=T_{v i b_{1}}=T_{v i b_{2}}=T_{v i b_{3}}
\end{gathered}
$$

However, as the asymmetric mode of $\mathrm{CO}_{2}\left(v_{3}\right)$ relaxes slower than the symmetric $\left(v_{1}\right)$ and bending $\left(v_{2}\right)$ vibrational modes [19], another two-temperature model can be considered where the asymmetric vibration is not in equilibrium with the other vibration modes. We then define it as the vibrational temperature, and consider all other temperatures equal to the rotational temperature:

$$
\begin{gathered}
T_{\text {rot }}=T_{\text {trans }}=T_{v i b_{1}}=T_{v i b_{2}} \\
T_{v i b}=T_{v i b_{3}}
\end{gathered}
$$

No previous measurements have been reported in the literature that would suggest either of the two models to be more appropriate for expansion tube conditions. Measurements under similar pressure conditions, such as those of Dang et al. [12] in a 20 mbar $\mathrm{CO}_{2}$ laser, and those of Klarenaar et al. [18] in a 6.7 mbar DC glow discharge, showed symmetric and bending vibrational mode temperatures close to the rotational temperatures, whereas the asymmetric mode temperature was significantly different. These measurements would support the second model (Eqn. 3, 4), 
however, the thermodynamic conditions in the expansion tube are significantly different. Furthermore, the latter model requires that the contribution of all vibration modes to the total rovibrational energies be identified, which is not possible for some of the high energy levels featured in the CDSD-4000 [15] database. Therefore, such a model is limited to low temperature conditions that can be modeled with the HITEMP-2010 [16] database (T $\leq 2200 \mathrm{~K})$. In this work, both models will be compared in the lower temperature free-flow region.

\section{Modeling of the free-flow radiation}

The 7-cm line-of-sight in the free-flow region is assumed to be homogeneous. $\mathrm{CO}_{2}$ spectra are calculated with RADIS using the HITEMP-2010 [16] database, a pressure of 17 mbar and a frozen $\mathrm{CO}_{2}$ concentration of $\mathrm{x}_{\mathrm{CO}_{2}}=0.61$ as given in Takayanagi et al. [6]. Nonequilibrium spectra are first calculated using the model of Eqn. 1, 2, which assumes equilibrium between all $\mathrm{CO}_{2}$ vibration modes. Figure 3 shows the spectra for various vibrational and rotational temperatures.

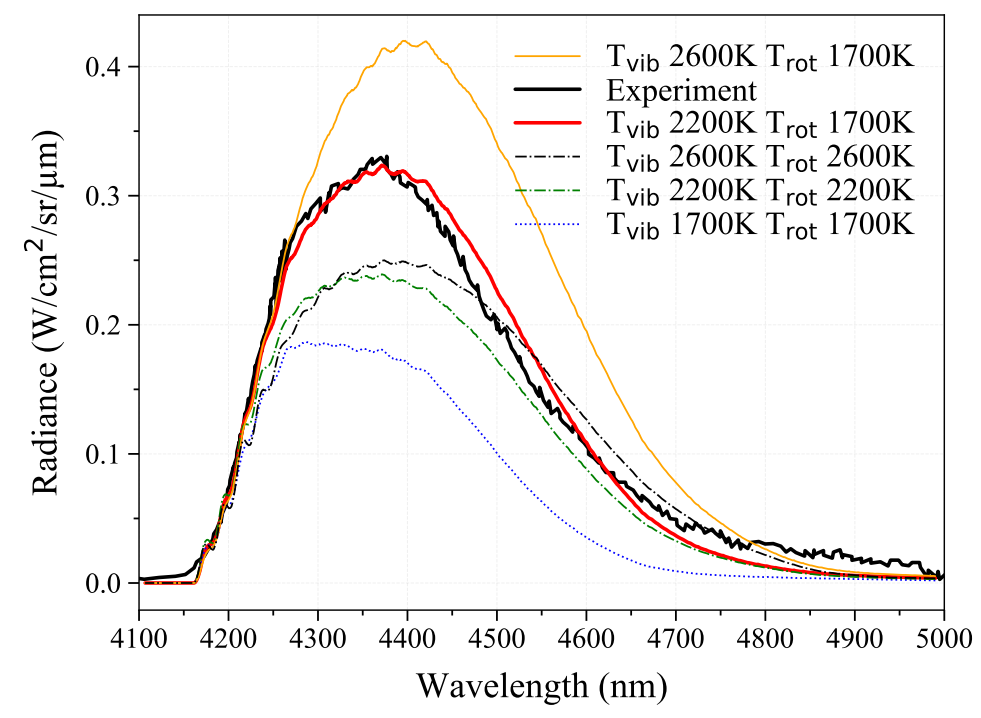

Fig. 3 Emission spectra in the free-flow (black [6]), compared with $\mathrm{CO}_{2}$ calculations in a frozen state $\left(\mathrm{x}_{\mathrm{CO}_{2}}=0.61\right.$, p=17 mbar) with the following nonequilibrium model: $T_{\text {rot }}, T_{v_{v i b}}=T_{v_{i b}}=T_{v_{i b}}=T_{v_{i b}}$

In general, the calculated spectra are much more similar in shape and amplitude to the experimental spectrum than those computed with SPRADIAN and presented in Ref. [6] (Fig. 22). The best agreement is obtained for $\mathrm{T}_{\text {rot }}=1700 \mathrm{~K}$ and $\mathrm{T}_{\mathrm{vib}}=2200 \mathrm{~K}$. The bandhead at $4.2 \mu \mathrm{m}$ is correctly reproduced. However, the agreement is not perfect, in particular for the region of the $\mathrm{CO}_{2}$ hot bands (> $4.4 \mu \mathrm{m}$ ). As suggested by [6], the presence of a heterogeneous flow with hotter $\mathrm{CO}_{2}$ slabs may be an explanation for the discrepancy. However, adding a hotter $\mathrm{CO}_{2}$ slab would also overpredict the radiation 
around $4.6 \mu \mathrm{m}$, as shown in Fig. 3 for the calculation at $2600 \mathrm{~K}$, which is already underestimated because it is slightly above the vaid temperature range of HITEMP-2010. Spatially-resolved spectra would be needed to close this issue.

Another possible reason for the discrepancy could be the presence of $\mathrm{CO}$ infrared emission. We added nonequilibrium $\mathrm{CO}$ emission to our simulations, assuming that the $\mathrm{CO}$ concentration remains frozen with $\mathrm{x}_{\mathrm{CO}}=0.26$. The $\mathrm{CO}$ rotational temperature is set equal to that of $\mathrm{CO}_{2}$, and the $\mathrm{CO}$ vibrational temperature $\mathrm{T}_{\mathrm{CO}}$ is set equal to that of $\mathrm{CO}_{2}$. However, the inclusion of $\mathrm{CO}$ made no significant changes to the spectra of Fig. 3. Only $\mathrm{CO}$ with vibrational temperature much higher than the $\mathrm{CO}_{2}$ vibrational temperature can yield quantitative changes. In Figure 4, we include the emission of nonequilibrium CO with a vibrational temperature of $4000 \mathrm{~K}$ to the $\mathrm{T}_{\mathrm{rot}}=1700 \mathrm{~K}, \mathrm{~T}_{\mathrm{vib}}=2200 \mathrm{~K}$ spectrum of Fig ??. The emission of $\mathrm{CO}$ with a vibrational temperature of $2200 \mathrm{~K}$ is shown for reference. The addition is enough to reproduce the experimental spectrum in the $4.8-4.9 \mu \mathrm{m}$ region, however, there is about a factor of 2 between the vibrational temperature of $\mathrm{CO}_{2}$ and $\mathrm{CO}$. In the measurements of Klarenaar et al. [18] in a DC glow at similar pressure, the $\mathrm{CO}$ temperature was found to be generally much higher than the vibrational temperature of the bending and symmetric modes of $\mathrm{CO}_{2}$, but it remained comparable with the asymmetric temperature $\mathrm{T}_{\mathrm{vib}_{3}}$. In our model, $\mathrm{T}_{\mathrm{vib}}$ remained equal to $2200 \mathrm{~K}$. Without further confirmation of the possibly large nonequilibrium between $\mathrm{CO}_{\text {and }} \mathrm{CO}_{2}$ vibrational temperatures, we did not retain the adjustment and the $\mathrm{CO}$ vibrational temperature is set equal to that of $\mathrm{CO}_{2}$.

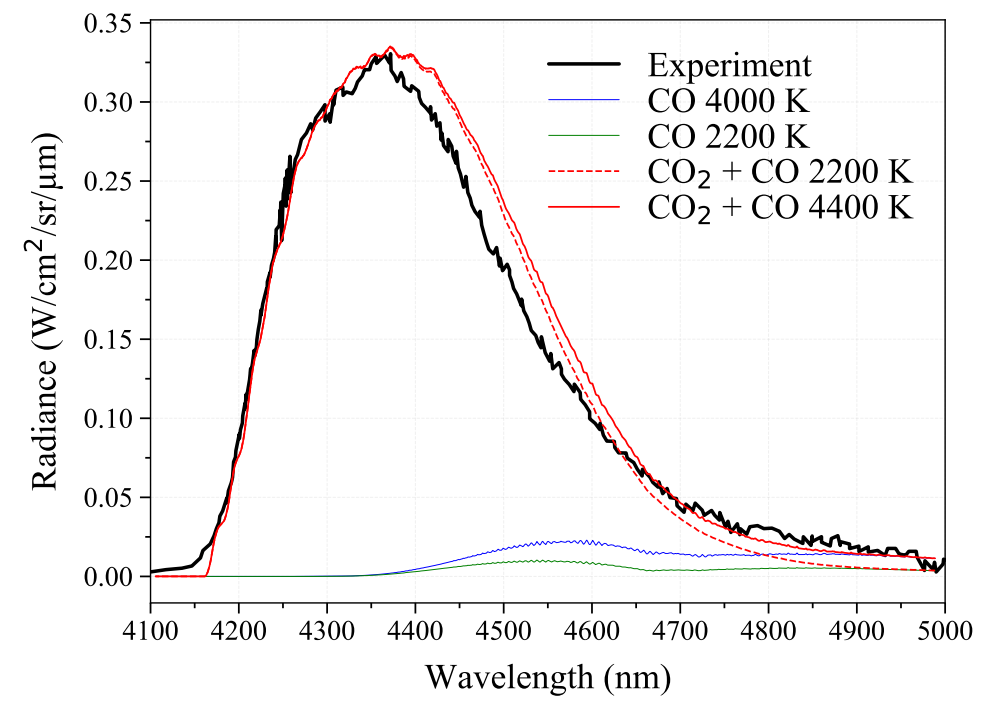

Fig. 4 Contribution of nonequilibrium CO at $\mathrm{T}_{\text {vib }}=2200 \mathrm{~K}$ (green) and $4400 \mathrm{~K}$ (blue) to the total line-of-sight emission (dashed and solid red, respectively). $x_{\mathrm{CO}_{2}}=0.61, x_{\mathrm{CO}}=0.26, p=17 \mathrm{mbar}, \mathrm{T}_{\text {rot }}=1700 \mathrm{~K}, \mathrm{~T}_{\mathbf{v i b}_{1,2,3}}=2200 \mathrm{~K}$.

A broad range of nonequilibrium conditions was calculated in RADIS using the $\mathrm{CO}_{2}$ nonequilibrium model of Eqn. 1, 2, and the $\mathrm{CO}$ nonequilibrium model described previously. Figure 5 shows the residual difference between the computed and measured spectra for various combinations of vibrational and rotational temperatures between 1600 and $2600 \mathrm{~K}$ (white dots). The best agreement with the experimental spectrum is obtained for $\mathrm{T}_{\text {rot }}=1700 \mathrm{~K}$ and 
$\mathrm{T}_{\mathrm{vib}_{1}}=\mathrm{T}_{\mathrm{vib}_{2}}=\mathrm{T}_{\mathrm{vib}_{3}}=\mathrm{T}_{\mathrm{CO}}=2200 \mathrm{~K}$. The fitted rotational temperature is close to the value measured by Takayanagi et al. [6], $\mathrm{T}_{\mathrm{rot}}=1690 \mathrm{~K}$. The vibrational temperature is also higher than the rotational temperature, as suggested by the adjusted parameters of [6], and characteristic of a fast expanding flow. However, the measured departure from nonequilibrium in the free flow is much smaller than predicted by the CFD simulations of Ref. [6] $\left(\mathrm{T}_{\mathrm{rot}}=1690 \mathrm{~K}\right.$ and $\left.\mathrm{T}_{\mathrm{vib}}=4000 \mathrm{~K}\right)$.

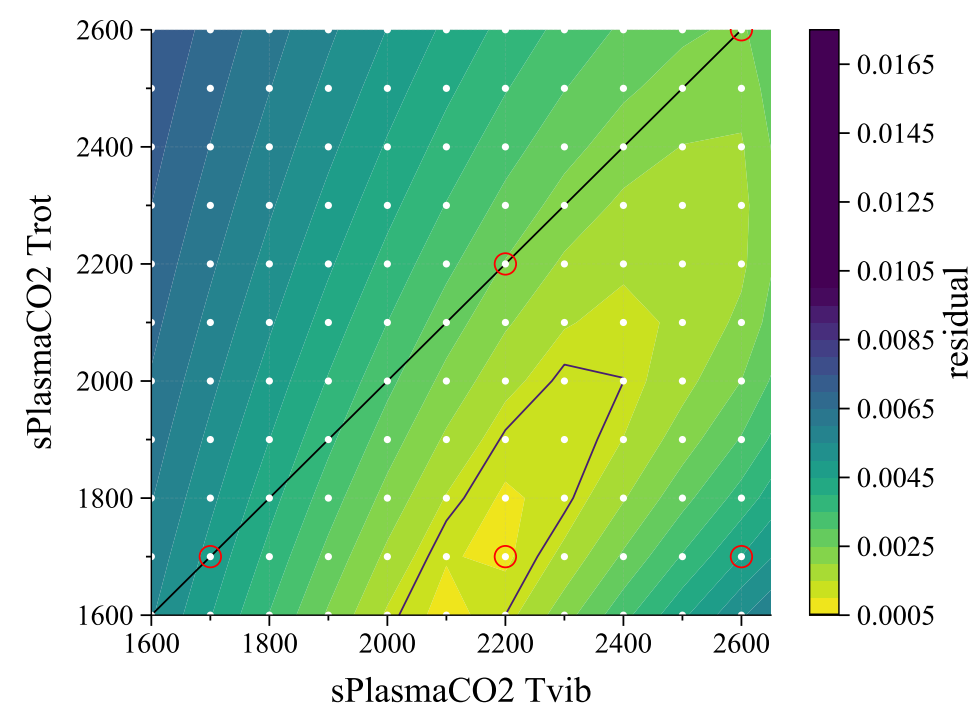

Fig. 5 Residual of nonequilibrium calculation relative to the free flow spectrum [6]. The minimum is obtained for $T_{\text {rot }}=1700 \mathrm{~K}, \mathrm{~T}_{\mathrm{vib}_{1,2,3}}=2200 \mathrm{~K}$. Red circle spectra are shown in Fig. 3 .

We then consider the second $\mathrm{CO}_{2}$ nonequilibrium model (Eqn. 3, 4), where the vibrational temperature of the $\mathrm{CO}_{2}$ asymmetric mode $\mathrm{T}_{\mathrm{vib}_{3}}$ is in nonequilibrium. $\mathrm{CO}$ emission is also included. In this model, the $\mathrm{CO}$ vibrational temperature is set equal to $\mathrm{T}_{\mathrm{vib}_{3}}$, as suggested by the measurements of Klarenaar et al. [18] at similar pressure. However,the contribution of $\mathrm{CO}$ is expected to be negligible as was shown in Fig. ??.

Figure 6 shows the spectra calculated with this model. The agreement with the experimental spectrum is not as good as when using the first model (Fig. 3). In particular, the bandhead at $4.2 \mu \mathrm{m}$ is not as well reproduced as when all of the vibrational modes of $\mathrm{CO}_{2}$ share a same vibrational temperature. All conditions of Fig. 5 were also calculated and are shown on Figure 7. The best agreement is achieved for temperatures of $T_{r t}=T_{\text {vib }_{1}}=T_{\text {vib }_{2}}=2200 \mathrm{~K}, T_{\text {vib }_{3}}=2500 \mathrm{~K}$. The measured rotational temperature is slightly higher than the $1690 \mathrm{~K}$ temperature of Takayanagi et al. [6], and the residuals in Fig. 7 are about twice higher as in Fig. 5.

In conclusion, our calculations suggest that in this particular experiment, the free-flow spectrum is better reproduced by a nonequilibrium model assuming that all $\mathrm{CO}_{2}$ vibration modes share a same vibrational temperature different from the rotational temperature, as in Eqn. 1, 2. Specifically, we found $T_{\text {rot }}=1700 \mathrm{~K}$ and $\mathrm{T}_{\mathrm{vib}_{1}}=\mathrm{T}_{\mathrm{vib}_{2}}=\mathrm{T}_{\mathrm{vib}_{3}}=2200 \mathrm{~K}$. The 


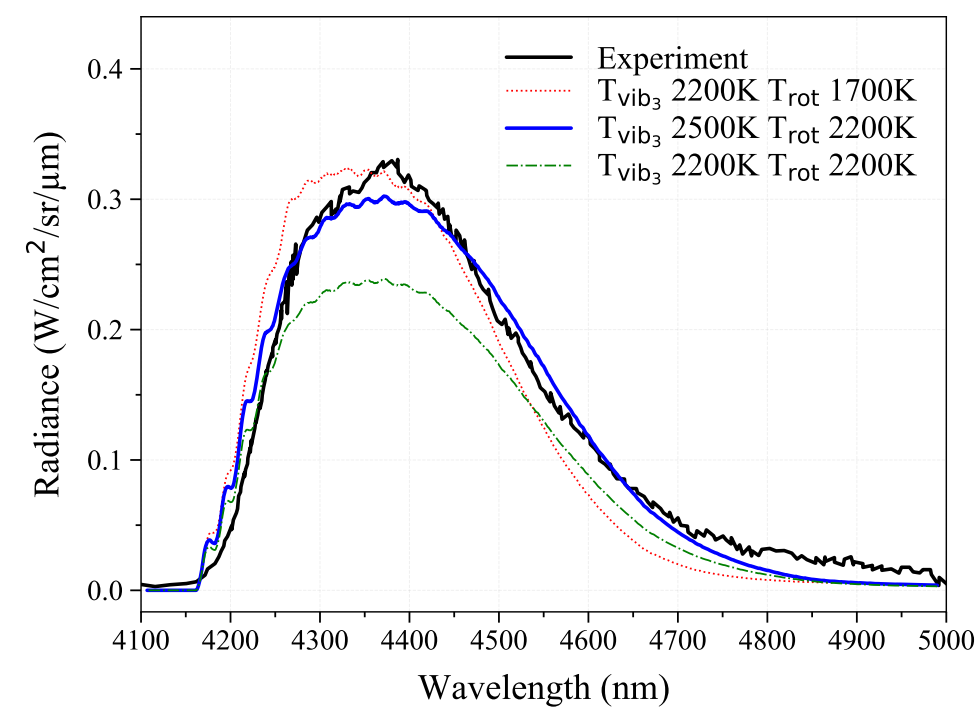

Fig. 6 Emission spectra in the free-flow (black [6]), compared with calculations with $\mathrm{CO}_{2}$ in a frozen state

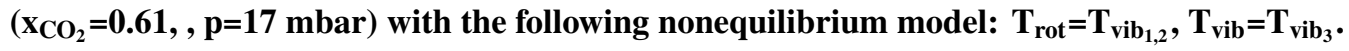

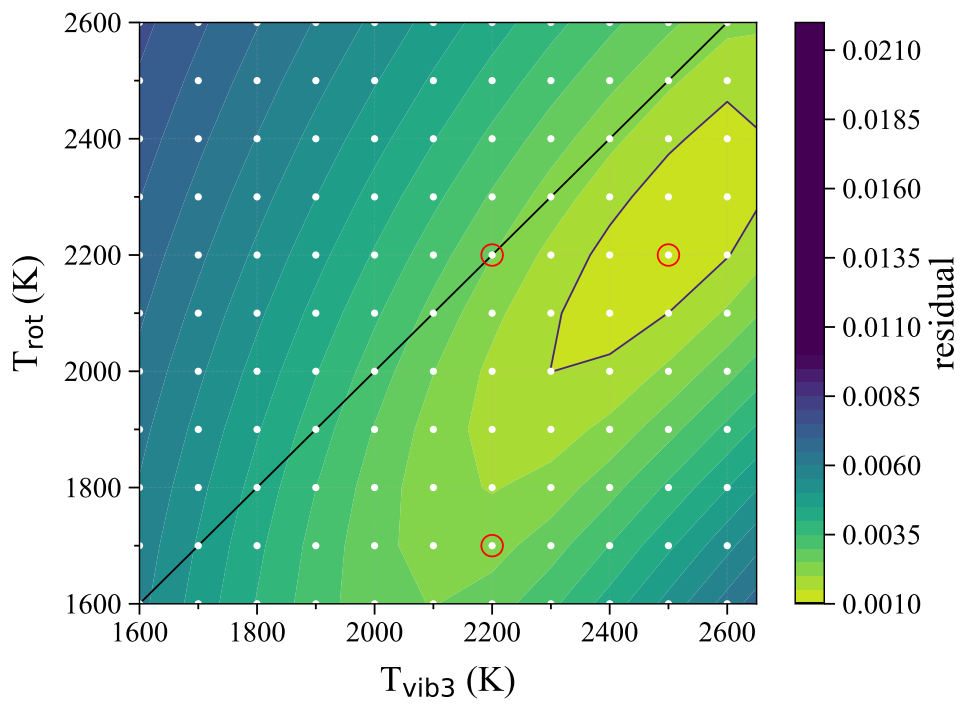

Fig. 7 Residual of nonequilibrium calculation relative to the free flow spectrum [6]. The minimum is obtained for $T_{\text {rot }}=T_{\text {vib }_{1,2}}=2200 \mathrm{~K}, T_{\text {vib }_{3}}=2500 \mathrm{~K}$. Red circle spectra are shown in Fig. 6.

departure from equilibrium is limited, and all vibration modes seem to be in equilibrium. The spectrum is dominated by $\mathrm{CO}_{2}$ emission and the contribution of $\mathrm{CO}$ is negligible. 


\section{Modeling of the forebody radiation}

We now consider the line-of-sight spectrum measured in the front part of the model. This spectrum has not been analyzed previously. This spectrum contains radiation from both the free flow and from the forebody shock layer, as shown in Fig. 1. Using Fig. 21 in Ref. [6], we estimated the forebody path length to be about $1 \mathrm{~cm}$. This is an approximation, but it is sufficient to analyze the main features of the forebody emission. Thus, our line-of-sight model is a $1 \mathrm{~cm}$ slab corresponding to the shock layer, surrounded by two $3 \mathrm{~cm}$ slabs corresponding to the free-flow, for a total of $7 \mathrm{~cm}$. The free-flow conditions are taken as those determined in Section III, i.e., $\mathrm{T}_{\mathrm{rot}}=1700 \mathrm{~K}$ and $\mathrm{T}_{\mathrm{vib}_{1}}=\mathrm{T}_{\mathrm{vib}_{2}}=\mathrm{T}_{\mathrm{vib}_{3}}=\mathrm{T}_{\mathrm{vib}}(\mathrm{CO})=2200 \mathrm{~K}$. Because the free-flow slabs are not optically thin, the RADIS line-of-sight module is used to solve the radiative transfer equation.

«««< Updated upstream The shock-layer conditions are calculated with the CEA code [20] for pre-shock conditions corresponding to those of the free-flow, i.e., $\mathrm{v}=5.8 \mathrm{~km} / \mathrm{s}$ and mole fractions $\mathrm{x}_{\mathrm{CO}_{2}}=0.61, \mathrm{x}_{\mathrm{CO}}=0.26$. Takayanagi et al. [6] (Table 7) calculated parameters of $17 \mathrm{mbar}$ and $\mathrm{T}_{\mathrm{vib}}=4000 \mathrm{~K}$ based on an initial parameters of $12 \mathrm{mbar}, \mathrm{T}_{\mathrm{vib}}=1690 \mathrm{~K}$. Shock-layer conditions are very sensitive to these parameters. To estimate the pressure in the shock-layer, we approximate the free flow as being in thermal equilibrium at a temperature of $1690 \mathrm{~K}$. For free-flow pressures of 12 and $17 \mathrm{mbar}$, the post-shock pressures are 0.97 and 1.38 bar, respectively. In the following discussion, we assume that the pressure is $\mathrm{p}=1$ bar. Radiation in the shock layer is calculated assuming that the gas is under thermochemical equilibrium.

Figures 8, 9 and 10 show the line-of-sight emission spectra calculated for shock-layer temperatures of 3500, 4000 and $45000 \mathrm{~K} .=======$ The pressure in the shock-layer is calculated with the CEA code [20] for pre-shock conditions corresponding to those of the free-flow, i.e., $\mathrm{v}=5.8 \mathrm{~km} / \mathrm{s}$ and mole fractions $\mathrm{x}_{\mathrm{CO}_{2}}=0.61, \mathrm{x}_{\mathrm{CO}}=0.26$. Takayanagi et al. [6] (Table 7) calculated free-flow parameters of 17 mbar, $T_{\text {vib }}=4000 \mathrm{~K}, \mathrm{~T}_{\mathrm{rot}}=1690 \mathrm{~K}$ to match the shock standoff distance. For a free-flow pressure of 17 mbar, assuming thermal equilibrium at a temperature of 1690 and $4000 \mathrm{~K}$, the post-shock pressure is 1.49 and 0.64 bar, respectively. In the following discussion, we assume that the pressure in the shock-layer is on the order of $\mathrm{p}=1$ bar.

Furthermore, the gas in the shock layer is assumed to be at thermochemical equilibrium. This assumption is supported by the CFD calculations of [6] (Fig. 18), who observed that the shock-layer flow was close to thermodynamic equilibrium.

Line-of-sight emission spectra are calculated for shock-layer temperatures of 3500, 4000 and 4500 K. »»»»> Stashed changes The conditions of the simulations are summarized in Table 1. Other calculations were also performed from $3000 \mathrm{~K}$ to $11,000 \mathrm{~K}$. 
Table 1 Simplified 3-slab model for RADIS simulations of the forebody line-of-sight emission.

\begin{tabular}{llll}
\hline Line-of-sight & Fig. 8 & Fig. 9 & Fig. 10 \\
\hline \hline \multirow{2}{*}{ Free-stream: } & $\mathrm{T}_{\text {rot }}=\mathrm{T}_{\text {trans }}=1690 \mathrm{~K}$ & & \\
Two 3-cm nonequilibrium slabs & $\mathrm{T}_{\mathrm{vib}}\left(\mathrm{CO}_{2}\right)=\mathrm{T}_{\mathrm{vib} 1}=\mathrm{T}_{\mathrm{vib} 2}=\mathrm{T}_{\mathrm{vib} 3}=\mathrm{T}_{\mathrm{vib}}(\mathrm{CO})=2200 \mathrm{~K}$ \\
& $\mathrm{x}_{\mathrm{CO}}=0.257, \mathrm{x}_{\mathrm{CO} 2}=0.606, \mathrm{p}=17 \mathrm{mbar}$ & \\
\hline Shock-layer: 1-cm slab under & $\mathrm{T}=3500 \mathrm{~K}, \mathrm{p}=1 \mathrm{bar}$ & $\mathrm{T}=4000 \mathrm{~K}, \mathrm{p}=1 \mathrm{bar}$ & $\mathrm{T}=4500 \mathrm{~K}, \mathrm{p}=1$ bar \\
thermochemical equilibrium & $\mathrm{x}_{\mathrm{CO}_{2}=0.130, \mathrm{x}_{\mathrm{CO}}=0.514}$ & $\mathrm{x}_{\mathrm{CO}_{2}=0.027, \mathrm{x}_{\mathrm{CO}}=0.520}$ & $\mathrm{x}_{\mathrm{CO}_{2}=0.005, \mathrm{x}_{\mathrm{CO}}=0.506}$ \\
\hline \hline
\end{tabular}

For these calculations, RADIS uses the CDSD-4000 [15] database and is interfaced with the CANTERA code [21] to calculate the equilibrium $\mathrm{CO}_{2}$ and $\mathrm{CO}$ concentrations. At very high temperature (11,000 K), $\mathrm{CO}$ and $\mathrm{CO}_{2}$ are both fully dissociated in the shock-layer and the line-of-sight emission spectrum is entirely due to the free flow component. At $3500 \mathrm{~K}$, the emission spectrum is dominated by the contribution of $\mathrm{CO}_{2}$ in the shock-layer. As the temperature increases, the $\mathrm{CO}_{2}$ equilibrium concentrations falls and the overall radiation intensity decreases. $\mathrm{CO}$ emission becomes stronger than $\mathrm{CO}_{2}$ emission above $4000 \mathrm{~K}$.

The high temperature CO emission spectrum starts above $4294 \mathrm{~nm}$, which corresponds to the reversal of the $v^{\prime}=1 \rightarrow v^{\prime \prime}=0$ band at about $\mathrm{J}=92$. Therefore, all emission below $4294 \mathrm{~nm}$ in the experimental spectrum can only be attributed to $\mathrm{CO}_{2}$ emission. Above $4294 \mathrm{~nm}$, the calculated CO emission spectrum features characteristic high temperature vibrational bandheads that are regularly spaced every about $55 \mathrm{~nm}$. The shifted experimental spectrum also features similar regularly spaced peaks between 4410 and $4790 \mathrm{~nm}$. These peaks are more visible when subtracting the free-flow component, as shown in Fig. 2. Another characteristic of CO emission is the emission plateau in the $4.8-5 \mu \mathrm{m}$ region, which corresponds to optically thick $\mathrm{CO}$ emission lines in the calculated spectra.

The $3500 \mathrm{~K}$ spectrum (Fig. 8) does not reproduce the $4.8-5 \mu \mathrm{m}$ region well, and significantly overestimates the total intensity. The $4500 \mathrm{~K}$ spectrum (Fig. 10) also fails to reproduce the experimental spectrum, particularly in the $4.2-$ $4.3 \mu \mathrm{m}$ region and above $4.6 \mu \mathrm{m}$. the measured intensity in the $4.2-4.3 \mu \mathrm{m}$ region is slightly higher than in the case of the free-flow (Fig. 2), which proves the presence of additional $\mathrm{CO}_{2}$ emission in the shock layer slab. However, under the chemical equilibrium assumption, the $\mathrm{CO}_{2}$ emission is negligible at $4500 \mathrm{~K}$. Finally, the line-of-sight spectrum corresponding to a shock-layer temperature of $\mathrm{T}=4000 \mathrm{~K}$ gives the best agreement with the experimental spectrum, both in terms of shape and absolute intensity. We conclude that the emission of the shock-layer can reasonably be approximated by that of a $1 \mathrm{~cm}$ slab in thermochemical equilibrium at $\mathrm{T}=4000 \pm 500 \mathrm{~K}$. 


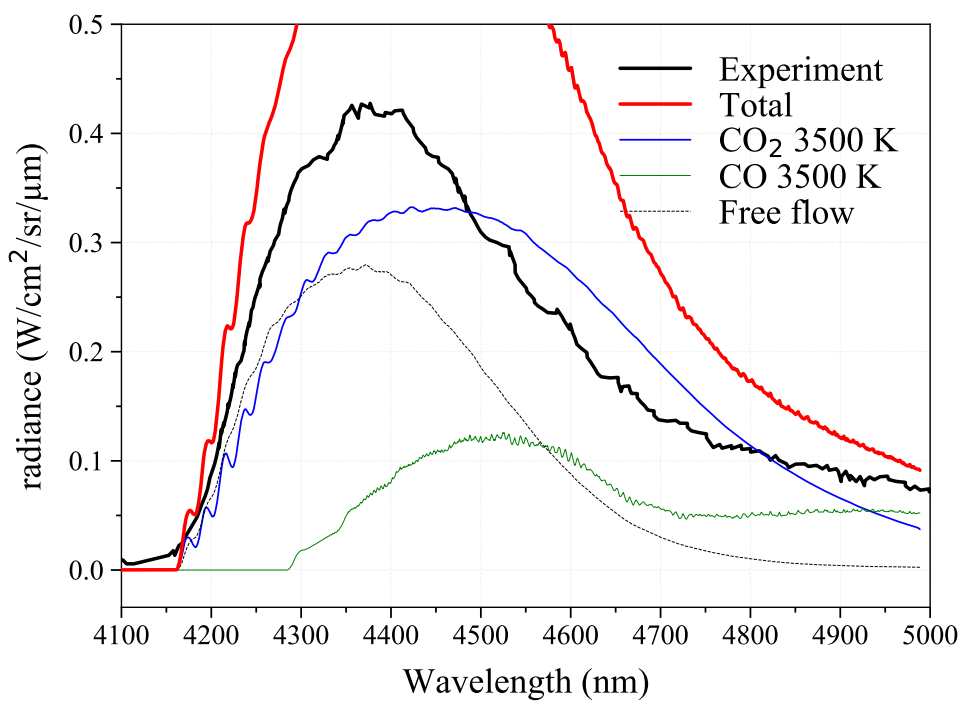

Fig. 8 Measured spectrum across the shock layer [6] (black), compared to the line-of-sight calculation (red) including two nonequilibrium free-flow slabs (dashed) and one equilibrium slab at $3500 \mathrm{~K}\left(\mathrm{CO}_{2}\right.$ : blue, $\mathrm{CO}$ : green).

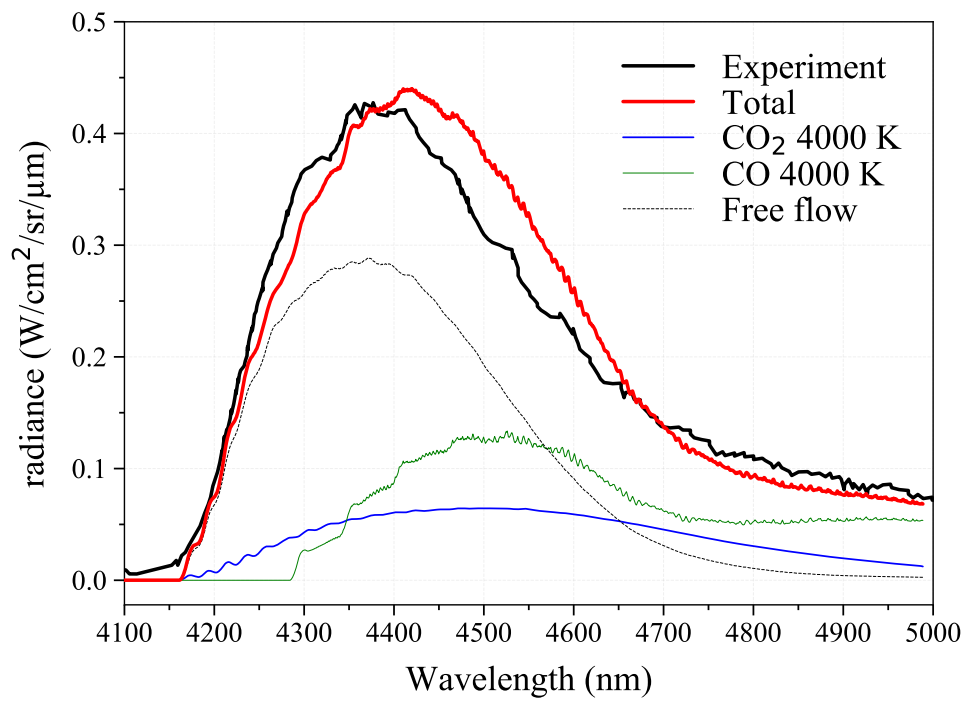

Fig. 9 Measured spectrum across the shock layer [6] (black), compared to the line-of-sight calculation (red) including two nonequilibrium free-flow slabs (dashed) and one equilibrium slab at $4000 \mathrm{~K}\left(\mathrm{CO}_{2}\right.$ : blue, $\mathrm{CO}$ : green).

\section{Conclusion}

The RADIS $[9,10]$ nonequilibrium spectral code was used to reanalyze the free-flow radiation measured in the expansion-tube experiment of Ref. [6]. Excellent agreement was achieved using a homogeneous spatial model and a slightly nonequilibrium distribution, which confirms the nonequilibrium hypothesis of Takayanagi et al. [6]. A comparison between different nonequilibrium models suggested that all $\mathrm{CO}_{2}$ vibration modes share a common vibrational 


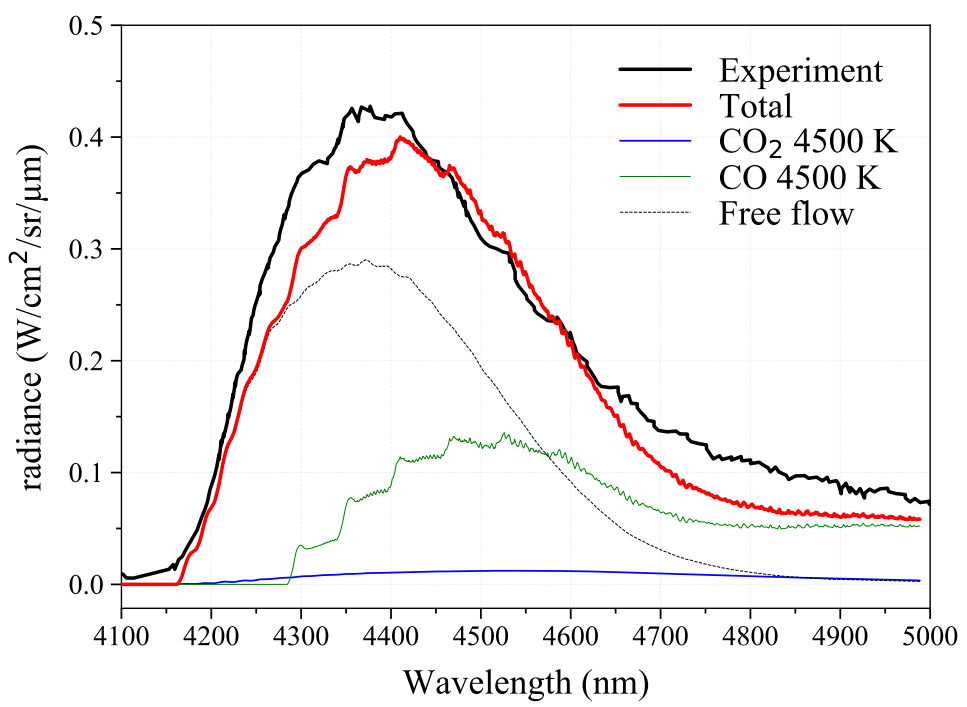

Fig. 10 Measured spectrum across the shock layer [6] (black), compared to the line-of-sight calculation (red) including two nonequilibrium free-flow slabs (dashed) and one equilibrium slab at $4500 \mathrm{~K}\left(\mathrm{CO}_{2}\right.$ : blue, $\mathrm{CO}$ : green).

temperature $(2200 \mathrm{~K})$ which is equal to the $\mathrm{CO}$ vibrational temperature and slightly above the rotational temperature $(1690 \mathrm{~K})$. The study was extended to do the first modeling of the spectral emission within the shock-layer in front of the model. It was shown that the forebody radiation corresponds to that of a plasma in thermochemical equilibrium at a temperature of $4000 \pm 500 \mathrm{~K}$, and that the measured experimental spectrum comprises an about equal contribution of $\mathrm{CO}_{2}$ and $\mathrm{CO}$ emission.

\section{References}

[1] Johnston, C., Brandis, A., and Sutton, K., "Shock Layer Radiation Modeling and Uncertainty for Mars Entry," 43rd AIAA Thermophysics Conference, American Institute of Aeronautics and Astronautics, Reston, Virigina, 2012, pp. 1-43. doi:10.2514/6.2012-2866.

[2] Brandis, A., Johnston, C., Panesi, M., Cruden, B., Prabhu, D., and Bose, D., "Investigation of Nonequilibrium Radiation for Mars Entry," 51st AIAA Aerospace Sciences Meeting including the New Horizons Forum and Aerospace Exposition, American Institute of Aeronautics and Astronautics, Reston, Virigina, 2013. doi:10.2514/6.2013-1055.

[3] Lino Da Silva, M., and Beck, J., "Contribution of CO2 IR Radiation to Martian Entries Radiative Wall Fluxes," 49th AIAA Aerospace Sciences Meeting including the New Horizons Forum and Aerospace Exposition, American Institute of Aeronautics and Astronautics, Reston, Virigina, 2011. doi:10.2514/6.2011-135.

[4] Cruden, B. A., Brandis, A. M., White, T. R., Mahzari, M., and Bose, D., "Radiative Heating During Mars Science Laboratory 
Entry: Simulation, Ground Test, and Flight," Journal of Thermophysics and Heat Transfer, Vol. 30, No. 3, 2016 , pp. 642-650. doi:10.2514/1.T4798.

[5] Rouzaud, O., Tesse, L., Soubrie, T., Soufiani, A., Riviere, P., and Zeitoun, D., "Influence of Radiative Heating on a Martian Orbiter," Journal of Thermophysics and Heat Transfer, Vol. 22, No. 1, 2008, pp. 10-19. doi:10.2514/1.28259.

[6] Takayanagi, H., Lemal, A., Nomura, S., and Fujita, K., "Measurements of Carbon Dioxide Nonequilibrium Infrared Radiation in Shocked and Expanded Flows," Journal of Thermophysics and Heat Transfer, Vol. 32, No. 2, 2018, pp. 483-494. doi:10.2514/1.T5200.

[7] Gu, S., Morgan, R. G., and McIntyre, T. J., "Study of the Afterbody Radiation during Mars Entry in an Expansion Tube," 55th AIAA Aerospace Sciences Meeting, American Institute of Aeronautics and Astronautics, Reston, Virginia, 2017. doi:10.2514/6.2017-0212.

[8] Fujita, K., Takashi, A., and Abe, T., "SPRADIAN, Structured Package for Radiation Analysis:Theory and Application,” 1997.

[9] Pannier, E., "RADIS: a Nonequilibrium Infrared Radiative Solver: Source Code and User Guide,” , 2018. URL https : //github.com/radis/radis.

[10] Pannier, E., O Laux, C., and Laux, C. O., "RADIS : A Nonequilibrium Line-by-Line Radiative Code for CO2 and HITRAN-like database species," Journal of Quantitative Spectroscopy and Radiative Transfer, 2018, pp. 1-35. doi:10.1016/j.jqsrt.2018.09.027.

[11] Depraz, S., Perrin, M., Rivière, P., and Soufiani, A., "Infrared emission spectroscopy of CO2 at high temperature. Part II: Experimental results and comparisons with spectroscopic databases," Journal of Quantitative Spectroscopy and Radiative Transfer, Vol. 113, No. 1, 2012, pp. 14-25. doi:10.1016/j.jqsrt.2011.09.013.

[12] Dang, C., Reid, J., and Garside, B. K., "Detailed vibrational population distributions in a CO2 laser discharge as measured with a tunable diode laser," Applied Physics B Photophysics and Laser Chemistry, Vol. 27, No. 3, 1982, pp. 145-151. doi:10.1007/BF00694640.

[13] Packan, D., Laux, C. O., Gessman, R. J., Pierrot, L., and Kruger, C. H., "Measurement and Modeling of OH, NO, and CO Infrared Radiation at 3400 K,' Journal of Thermophysics and Heat Transfer, Vol. 17, No. 4, 2003, pp. 450-456. doi:10.2514/2.6803.

[14] Cruden, B. A., Brandis, A. M., and Prabhu, D. K., "Measurement and Characterization of Mid-wave Infrared Radiation in CO2 Shocks," 11th AIAA/ASME Joint Thermophysics and Heat Transfer Conference, American Institute of Aeronautics and Astronautics, Reston, Virginia, 2014. doi:10.2514/6.2014-2962.

[15] Tashkun, S. A., and Perevalov, V. I., "CDSD-4000: High-resolution, high-temperature carbon dioxide spectroscopic databank," Journal of Quantitative Spectroscopy and Radiative Transfer, Vol. 112, No. 9, 2011, pp. 1403-1410. doi: 10.1016/j.jqsrt.2011.03.005. 
[16] Rothman, L. S., Gordon, I. E., Barber, R. J., Dothe, H., Gamache, R. R., Goldman, A., Perevalov, V. I., Tashkun, S. A., and Tennyson, J., "HITEMP, the high-temperature molecular spectroscopic database," Journal of Quantitative Spectroscopy and Radiative Transfer, Vol. 111, No. 15, 2010, pp. 2139-2150. doi:10.1016/j.jqsrt.2010.05.001.

[17] Guelachvili, G., de Villeneuve, D., Farrenq, R., Urban, W., and Verges, J., "Dunham coefficients for seven isotopic species of CO,” Journal of Molecular Spectroscopy, Vol. 98, No. 1, 1983, pp. 64-79. doi:10.1016/0022-2852(83)90203-5.

[18] Klarenaar, B. L. M., Engeln, R., van den Bekerom, D. C. M., van de Sanden, M. C. M., Morillo-Candas, A. S., and Guaitella, O., "Time evolution of vibrational temperatures in a CO 2 glow discharge measured with infrared absorption spectroscopy," Plasma Sources Science and Technology, Vol. 26, No. 11, 2017, p. 115008. doi:10.1088/1361-6595/aa902e.

[19] Witteman, W. J., The CO2 laser, Springer-Verlag, 1987.

[20] NASA, “CEARUN,”, 1971. URL https://cearun.grc.nasa.gov/.

[21] Goodwin, D. G., Moffat, H. K., and Speth, R. L., "Cantera: An Object-oriented Software Toolkit for Chemical Kinetics, Thermodynamics, and Transport Processes," \urlhttp://www.cantera.org, 2017. doi:10.5281/zenodo.170284. 